\title{
A SIMSCAPE based design of a dual maximum power point tracker of a stand-alone photovoltaic system
}

\author{
Mohammed S. Ibbini, Abdullah H. Adawi
}

Department of Electrical Engineering, Jordan University of Science and Technology

\begin{tabular}{l}
\hline \hline Article Info \\
\hline Article history: \\
Received Jan 19, 2019 \\
Revised Jan 7, 2020 \\
Accepted Jan 16, 2020 \\
\hline Keywords: \\
Dual MPPT \\
GMPPT/LMPPT \\
MATLAB/SIMSCAPE \\
MATLAB/SIMULINK \\
Photovoltaic \\
\hline
\end{tabular}

\begin{abstract}
This paper presents the simulation of a dual maximum power point tracker (dual-MPPT) and attempt to get the global maximum power point GMPP under partial shading conditions for a solar photovoltaic module using MATLAB SIMSCAPE. Traditional single MPP trackers are less efficient than dual MPP trackers and have greater sensitivity to partial shading. By using dual MPP trackers, one can get several features such as the possibility of connecting two arrays with different string sizes or different solar azimuths or tilts within high efficiency. This paper focuses on making the photovoltaic system work at maximum possible power under partial shading condition by using dual MPP trackers to achieve the convergence toward the global maximum power point GMPP.
\end{abstract}

Copyright (C) 2020 Institute of Advanced Engineering and Science. All rights reserved.

\section{Corresponding Author:}

Mohammed Salameh Ibbini,

Departement of Electrical Engineering,

Jordan University of Science and Technology,

P.O.Box 3030, Irbid22110, Jordan.

Email: mohib@just.edu.jo

\section{INTRODUCTION}

MPPT stands for Maximum Power Point Tracker. It should be emphasized that the MPPT is not mechanical but an electronic device that forces the system to work at its maximum possible power. The electric power supplied by the photovoltaic panels is limited and is affected by temperature and solar radiation rate. Since the efficiency of the photovoltaic panels is very low, many techniques can be used to increase the amount of energy that can be drawn from sunlight. Solar system workers, designers, and customers, all benefit from applications of Dual MPPT [1-3].

Power converters that work without the MPPT circuit will result in operating below their required power level or in non-optimal operating conditions. The MPPT circuit permanently monitors the PV modules current and voltage, and then drive the system to operate on its maximum power point and hence, resulting in the highest extracted energy [4-6]. Power converters with dual-MPPT allow considerable cost savings, higher system design flexibility, and greater extracted power. One of the most important features of using dual MPPT is the possibility of connecting two arrays with different string sizes (Voc), different solar azimuths or tilts or different PV module types within high efficiency and without any technical problems. Connecting two arrays of PV panels are fixed at different tilt angles and/or longitudinal, different array sizes or different module types require two single MPPT power converters so using a dual MPPT will reduce costs and facilitate the design process [7].

Even when the arrays are in one direction, the use of the dual MPPT power converter is considered more reliable. If one of the two arrays subjected to partial shading or exposed to a malfunction, the second input will remain at the same efficiency and will not be affected by the other channel. Dividing the PV panels into two arrays on a dual MPPT power converter will increase the efficiency of the system because in case one array is damaged, the amount of output power of the other array at the second MPPT will not affect [8]. 
Depending on the national electric code, combiner fuse in each string should be used in case more than two PV strings connected to a single input of an inverter. This is as long as the string wiring is sized properly and there are no other current sources that can back feed into the strings. In the case of using a dual MPPT inverter, four arrays can be connected with it without any external combining hardware [9-10]. This paper is organized as follows; Section 2 explains the concept of partial shading also provides and illustrates the concept of MPPT and Dual MPPT and finally, an improved P\&O technique was used to access the GMPP under partial shading. Section 3 describes the PV module using SIMSCAPE. Finally, in Section 4, some conclusions and suggestions will be offered.

\section{METHOLODOGIES}

The energy extracted from photovoltaic panels depends on different factors such as temperature, irradiance, and efficiency. Moreover, photovoltaic panels are also limited by the physical structure of their photovoltaic cells. However, the efficiency of photovoltaic panels is very low. Different techniques can be used to increase the photovoltaic panel's extracted power. An intuitive solution is then to add more PV panels but will increase the space requirements and in a huge increase in the total cost of photovoltaic systems. However, one can also attempt to force the existing photovoltaic panels to continuously track its highest possible extracted power. To avoid the increment of the PV surface and consequently, the cost, a maximum power point tracking (MPPT) technique is used to force the system works at its maximum extracted power $[11,12]$.

SIMSCAPE is similar to SIMULINK in the sense of using block libraries but in plus, uses more the physical features of real devices and hence, is more suitable for physical components modeling. The non-directionality of SIMSCAPE element ports and their physical features allow their connection to be very similar to the connection of real components. Therefore, SIMSCAPE components can be connected as soon as their real counterpart is connectable. In SIMSCAPE, all the problems of flow or information are resolved and do not cause any difficulty $[13,14]$.

The basic element of a PV module is called a photovoltaic cell. More than one PV cell block can be used to form a PV module based on series and parallel connections cells. As an illustration, a string of six PV cells connected in series is shown in Figure 1 which that figure shows the irradiance to be the only input, the temperature is also being an input of the configurable parameters [15].

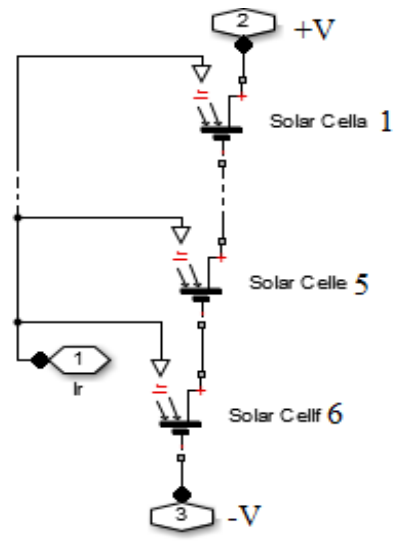

Figure1. 6 Solar Cells Connected in Series

A solar cell is modeled as a parallel connection of a current source, resistance Rp with two exponential diodes, all connected in series, with a resistor Rs. The model output current is simplified as:

$$
I=I p h-I s\left[e \frac{e^{V+I R s}}{A K T}-1\right]-\frac{V+I R s}{R p}
$$

While studying PV systems, many factors should be taken in the account especially in large PV systems, the radiation is usually non-uniform and temperature also is not the same on the surface of all PV panels. Clouds, high buildings and even trees can cause partial shading on PV systems. The amount of output power of PV arrays is proportional to the area of the PV modules that are exposed to the radiation and hence, partial shading, therefore, reduces the electrical power that can be drawn from the PV system. Partial shading causes an area of high temperature known as "hot spots" which can severely damage the corresponding cells. 
In modern PV modules, small electronic components are used as a part of the modules and are called bypass diodes. These diodes allow the current of un-shaded cells to be bypassed through shaded cells, usually, every module has two or three bypass diodes [16-18].

The main objective of employing MPPT is to force the system to operate at its maximum extracted power from PV panels under various environmental conditions [19, 20]. MPPT techniques differ in the number of sensors, cost, complexity, effectiveness and correct tracking for different irradiation and temperatures. MPPT does not require mechanical tracking to point out the PV module or system to the sun but rather an electronic scanning system that control the operating point in such a way that the PV system works at its maximum power, When environmental conditions such as temperature and irradiation change, the MPPT makes sure the PV system operates as close as possible to its maximum power operating point. It is then desired to design a controller that forces the PV system to operate at its maximum extracted power [21-23].

However, where one or more PV modules that form one array are shaded, then multiple local maxima will appear on the PV characteristics. The highest one of those local maxima is termed the global maximum power point. In the case of partial shading, traditional MPPT techniques fail to guarantee successful tracking of the GMPP [24]. The Perturb \& Observe technique is the most widely used algorithm in stand-alone PV systems. The technique consists of measuring the current and voltage and hence, the associated power $\mathrm{P}_{1}$ is computed. This is then followed by a small perturbation of the voltage, or the associated duty cycle of the DC-DC converter and the corresponding power $\mathrm{P}_{2}$ is then calculated. The power $\mathrm{p} 2$ is then compared to $\mathrm{p} 1$ and if the difference $\mathrm{P} 2-\mathrm{P}_{1}$ is positive then the perturbation is in the right direction. Otherwise, the perturbation is reversed and the procedure continues until the maximum power point is obtained. Finally, the maximum voltage $\mathrm{V}_{\mathrm{Mpp}}$ and current $\mathrm{I}_{\mathrm{Mpp}}$ are deduced.

One disadvantage of using $\mathrm{P} \& \mathrm{O}$ is its deviation from the maximum power point when atmospheric conditions change rapidly. Another drawback is its need for precise perturbation size to result in dynamical and steady-state operation performance [25]. P\&O technique is working very well under normal conditions. However, under partial shading conditions, the $\mathrm{P} \& \mathrm{O}$ technique fails to guarantee the operation at the global maximum power point (GMPP) and often falls on a local maximum power point (LMPP) which tends to reduce the efficiency of the $\mathrm{PV}$ system.

The improved $\mathrm{P} \& \mathrm{O}$ technique is an evolution of $\mathrm{P} \& \mathrm{O}$ technique, the most important property in this technique is splitting the P-V curve into several parts, every part has own duty cycle and hence, making the preliminary scanning of the PV system and storage the values of power on the P-V curve and the values of the duty cycles corresponding to them [26]. After the scanning process finishes, the technique works as conventional $\mathrm{P} \& \mathrm{O}$ at the highest recorded value until it reaches the global maximum power point, Figure 2 shows the improved $\mathrm{P} \& \mathrm{O}$ algorithm flow chart.

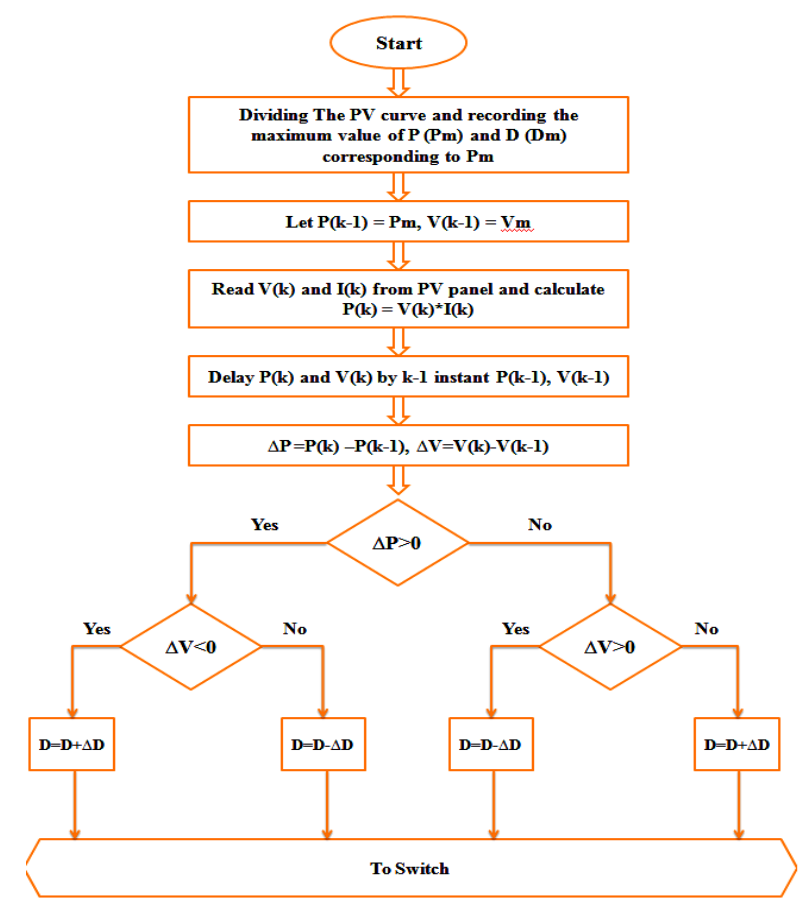

Figure 2. Improved $\mathrm{P} \& \mathrm{O}$ algorithm flow chart 
Using MATLAB/SIMSCAPE, dividing the PV curve can be implemented by dividing the duty cycle into the same number of parts. The value of the duty cycle for the first small part of the PV curve is equal to zero and one for the last small part. The duty cycle values for other parts can easily be calculated in the same way and they will locate between zero and one [27].

\section{SIMULATIONS, RESULTS AND ANALYSIS}

As mentioned earlier, the basic elements of a PV module is called a PV cell. In SIMSCAPE workspace, a PV cell block can be used to exactly simulate the behavior of a real PV cell. More than one PV cell block can be connected out of series and parallel to form a PV module. Figure 3 illustrates the SIMSCAPE block diagram of the PV system with single MPPT, and hence, Dual MPPT under partial shading condition is illustrated in Figure 4 [26, 27].

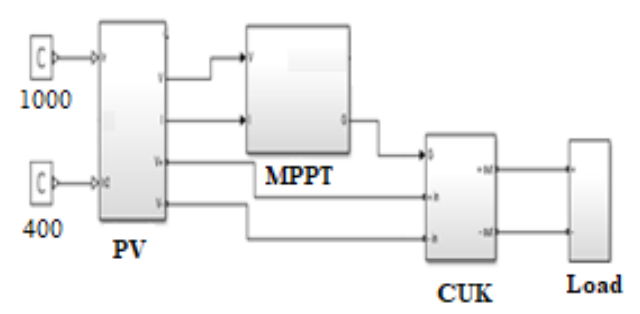

Figure 3. A single MPPT PV system SIMSCAPE model under partial shading conditions

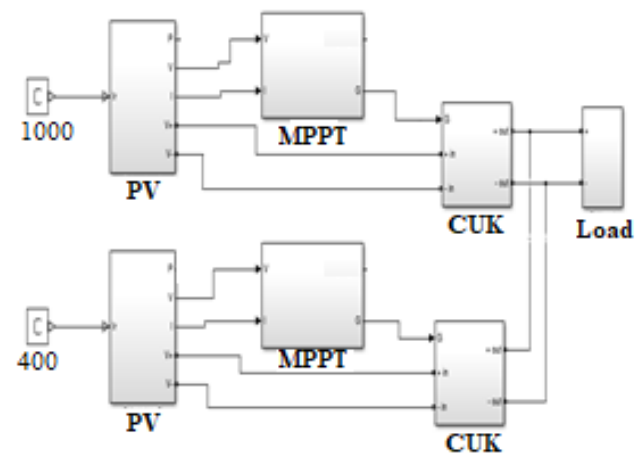

Figure 4. A dual MPPT PV system SIMSCAPE model under partial shading conditions

The adopted PV Cell specifications are as shown in Table 1. Where, NS is number of cells in series, $\mathrm{V}_{\mathrm{oc}}$ is Open circuit voltage, $\mathrm{I}_{\mathrm{sc}}$ is Open circuit voltage, $\mathrm{V}_{\mathrm{MPP}}$ is Open circuit voltage, $\mathrm{I}_{\mathrm{MPP}}$ is Current at MPP, $\mathrm{P}_{\max }$ is Maximum power. The two systems are tested under two radiation levels namely, 1000 and $400 \mathrm{~W} / \mathrm{m}^{2}$, and simulation results are shown in Figure 5 and 6. In the single MPPT case, the GMPP is shown to be $54 \mathrm{~W}$ as illustrated in Figure 5. However, the case of Dual MPPT results in a GMPP of $80 \mathrm{~W}$ as can be seen in Figure 6. Figure 7 illustrates the comparisons of the operation of the single and dual MPPT on the same time-scale. It is clear from the previous figures the effects of using dual MPPT on the total extracted possible power. By using the dual MPPT comparing to the single MPPT, the maximum extracted power was increased from $54 \mathrm{~W}$ to $80 \mathrm{~W}$ under the same condition. So this result shows that the efficiency of dual MPPT is many times bigger than the single MPPT, therefore, it is recommended to use this method.

Table1 1. The PV cell specifications

\begin{tabular}{cc}
\hline $\mathrm{NS}$ & 36 \\
\hline $\mathrm{V}_{\mathrm{oc}}$ & $22 \mathrm{~V}$ \\
$\mathrm{I}_{\mathrm{sc}}$ & $7.06 \mathrm{~A}$ \\
$\mathrm{~V}_{\mathrm{MPP}}$ & $18 \mathrm{~V}$ \\
$\mathrm{I}_{\mathrm{MPP}}$ & $6.67 \mathrm{~A}$ \\
$\mathrm{P}_{\max }$ & $120 \mathrm{~W}$ \\
\hline
\end{tabular}




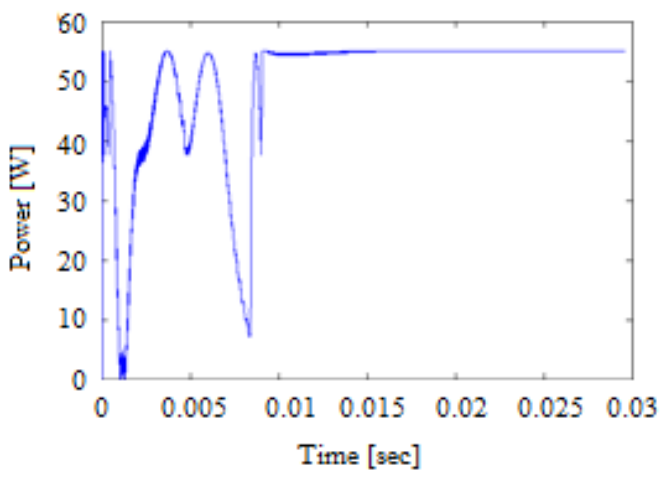

Figure 5. Power versus time when using single MPPT and improved P\&O technique

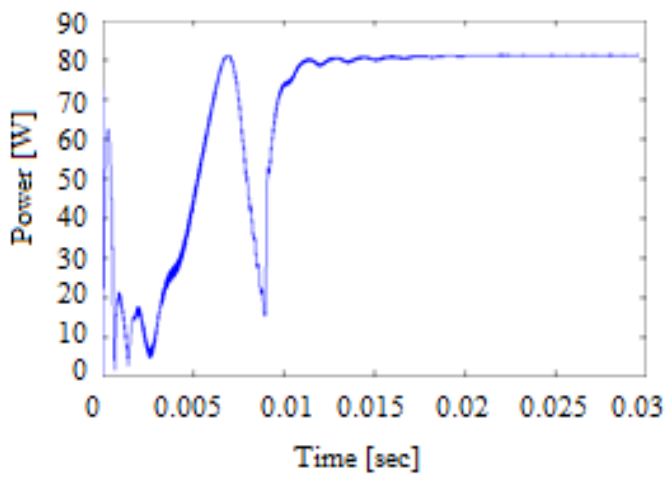

Figure 6. Power versus time when using dual MPPT and improved $\mathrm{P} \& \mathrm{O}$ technique

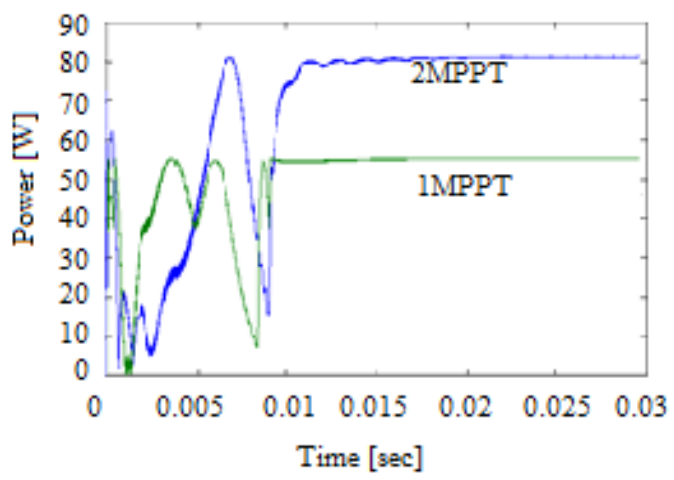

Figure 7. Power versus time when using single and dual MPPT with improved P\&O technique

\section{CONCLUSION}

In this paper, dual MPPT has been proposed and compared with a single MPPT. The simulation results show that the total extracted power in case of using dual MPPT is significantly maximized as opposed to the case of single MPPT especially under partial shading conditions. The proposed system was simulated using the mathematical equations of each component in the MATLAB/SIMSCAPE environment. The simulation analysis demonstrates that the improved P\&O technique can work very well under partial shading conditions and the PV system will work on its global maximum power point (GMPP).

\section{REFERENCES}

[1] G. Li, X. Shi, C. Fu, and G. Zhou, "Design and implementation of a novel MPPT controller based on sun tracking technology," IEEE International conference on Electrical Machines and Systems, ICEMS, pp. 2611-2615, 2008.

[2] R. K. Ismael Ackah, "Green growth in oil producing African countries: A panel data analysis of renewable energy demand," Renewable and Sustainable Energy Reviews, vol. 50, no. C, pp. 1157-1166, 2015.

[3] "Environment," National Geographic, [Online]. Available: http://environment.nationalgeographic.com

[4] "National Energy research Center (NERC)-Jordan," Feb 2012. [Online]. Available: www.nerc.gov.jo.

[5] E. S. Hrayshat, "Visibility of solar photovoltaics as an electricity generation source for Jordan," International Journal of Sustainable Engineering, vol. 34, no. 10, pp. 2133-2140, 2009.

[6] Kawar Group, "The international resource journal," Kawar Group, Jordan, 2011.

[7] D. L. King, W. E. Boyson, J. A. Kratochvill, "Photovoltaic array performance model," Sandia Report, Sandia National Laboratory, New Mexico, November, 2013.

[8] L. Ayompe, A. Duffy, S. J. McCormack, and M. Conlon, "Validated real-time energy models for small-scale grid-connected PV-systems," Energy, vol. 35, no. 10, pp. 4086-4091, 2010.

[9] C. Breyer, A. Gerlach, O. Beckel, and J. Schimd, "Value of solar PV electricity in MENA region," IEEE International Energy Conference, pp. 558-563, 2010.

[10] "SOPHIA, European Research infrastructure," [Online]. Available: http://www.sophia-ri.eu/

[11] T. Esram and P. L. Chapman, "Comparison of photovoltaic array maximum power point tracking techniques," IEEE Trans. Energy Conv., vol. 22, no. 2, pp. 439-449, 2007. 
[12] C. Keles; B. B. Alagoz, M. Akcin, A. Kaygusuz, and A. Karabiber, "A photovoltaicsystem model for MATLAB/Simulink simulations," IEEE 4 ${ }^{\text {th }}$ Int. Conf. on Pow. Eng., En. and Elec. Driv., pp. 1643-1647, 2013.

[13] P-W. Hsiao, C-H. Chang, and H-L. Tsai, "Accuracy improvement of practical PV model," Proceedings of SICE Annual Conference, Taipei, Taiwan, pp. 2725-2730, 2010.

[14] S. R. Chowdhury and H. Saha, "Maximum power point tracking of partially shaded solar photovoltaic arrays," Solar Energy Materials and Solar Cells, vol. 94, no. 9, pp. 1441-1447, 2010.

[15] T. A. Selmi, M. Bouzguenda, A. Gastli, and A. Masmoudi, "MATLAB/ Simulink based modelling of solar photovoltaic cell," International Journal Of Renewable Energy Research, vol. 2, no. 2, pp. 213-218, 2012.

[16] E. Karatepe, Syafaruddin, and T. Hiyama, "Simple and high-efficiency photovoltaic system under non-uniform operating conditions," IET Renewable Power Generat., vol. 4, no. 4, pp. 354-368, 2010.

[17] R. J. Mukti and A. Islam, "Modeling and performance analysis of PV module with maximum power point tracking in MATLAB/Simulink," Applied Solar Energy, vol. 51, no. 4, pp. 245-252, 2015.

[18] Y. Rambhowan and V. Oree, "Improving the dual-axis solar tracking system efficiency via drive power consumption optimization," Applied Solar Energy, vol. 50, no.2, pp. 74-80, 2014.

[19] S. K. Ismatkhodgaev, N. A. Matchanov, Sh. A. Azizov, and Sh. I. Suleymanov, "Advanced technologies of development of power engineering and energy supply of the republic economy," Applied Solar Energy, vol. 50, no. 3, pp. 191-195, 2014.

[20] H. B. Tolabi and S. Md. Ayob, "New technique for global solar radiation forecasting by simulated annealing and genetic algorithms using," Applied Solar Energy, vol. 50, no. 3, pp. 202-206, 2014.

[21] J-K. Shiau, Y-C. Wei, and B-C. Chen "A study on the fuzzy-logic-based solar power MPPT algorithms using different fuzzy input variables algorithms," Algorithms, vol. 8, no. 2, pp. 100-127, 2015.

[22] J. M. Enrique, J. M. Andujar, and M. A. Bohorquez, "A reliable, fast and low cost maximum power point tracker for photovoltaic applications," Solar Energy, vol. 84, no. 1, pp. 79-89, 2010.

[23] N. Pongratananukul, "Analysis and Simulation tools for solar array power systems," Doctoral Dissertation, University of Central Florida, Florida, 2005.

[24] S. Jain and V. Agarwal, "A new algorithm for rapid tracking of approximate maximum power point in photovoltaic systems," IEEE Power Electronics letter, vol. 2, no. 1, pp. 16-19, 2004

[25] G. Dzimano, "Modeling of photovoltaic systems," Master Thesis, The Ohio State University, 2008.

[26] M. S. Ibbini and A. H. Adawi, "A simscape based design of a global maximum power point tracker under partial shading condition," International Journal of Smart Grid and Clean Energy, vol. 8, no. 1, pp. 98-102, Jan 2019.

[27] Mohammed S. Ibbini, Abdullah H. Adawi, "Analysis and design of a maximum power point tracker for a standalone photo voltaic system using simscape," Int. J. of Adv. Trends in Comp. Sci. and Eng., vol. 8, no. 1, pp. 54-57, 2019.

\section{BIOGRAPHIES OF AUTHORS}

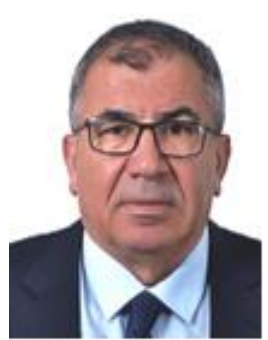

Mohammed Salameh Ibbini received his $\mathrm{Ph} . \mathrm{D}$ in electrical engineering from the University of Illinois at Urbana-Champaign, his M.sc. in electrical engineering from the University of Coloradoat Boulder and his B. Sc. in Electronics from the ENSEEC in France. He is currently Professor of electrical and biomedical engineering at Jordan University of Science \& Technology. $\mathrm{He}$ is currently the vice president of Jordan University of Science and Technology and had held different administrative and academic positions. Mohammed Ibbini has been professor of EE and BME at JUST since 2005, authoring and co-authoring over 70 articles and attending a huge number of international conferences. Professor Ibbini taught different courses in linear and nonlinear control, biomedical instrumentation, signal and systems and machines. His research interest includes but not limited to nonlinear control, renewable energy, feedback linearization, ultrasound and microwave cancer therapy, diabetes and bridging the gap between the university output and the work market needs. Prof. Ibbini is a strong advocate of hands-on, real life examples, project based learning, learning by doing and innovation in Engineering.

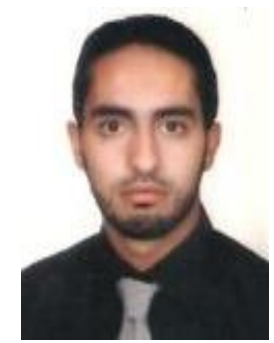

Abdullah Hamed Adawi is born in Saudia Arabia In 1990, I obtained a bachloer degree in electrical power engineering in 2012 from Albalqaa Applied University. I received my Master in 2019 in the field of power and control engineering from Jordan University of Science and Technology. 